Volume 12, No.3

Jul-Sep 2017

JURNAL IMMAH

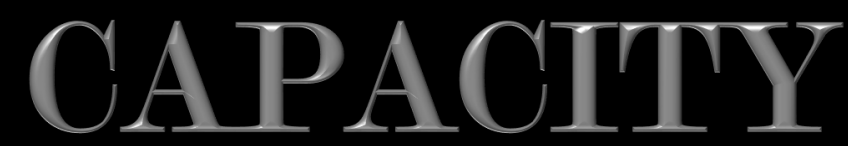




\title{
KAJIAN PEMBERIAN KREDIT DALAM RANGKA MENGURANGI RISIKO KEMACETAN PADA PT. BANK NEGARA INDONESIA (Persero) TbK SENTRA KREDIT KECIL MAKASSAR
}

\author{
Zulfikry Sukarno \\ STIEM Bongaya Makassar \\ email: fikry.hawk@gmail.com
}

\begin{abstract}
Abstrak
Penelitian ini bertujuan untuk mengetahui kredit di PT. Bank Negara Indonesia (Persero) Tbk Sentra Kredit Kecil Makassar memiliki kolektibiliti rendah, untuk mengetahui Rasio keuangan yang dominan akan mempengaruhi kolektibiliti nasabah pada PT. Bank Negara Indonesia (Persero) Tbk Sentra Kredit Kecil Makassar dan untuk mengetahui hubungan antara kolektibiliti dengan penilaian keuangan sesuai dengan perangkat aplikasi kredit pada PT. Bank Negara Indonesia (Persero) Tbk Sentra Kredit Kecil Makassar.

Penelitian ini menggunakan pendekatan kuantitatif dengan analisis regresi untuk melihat pengaruh dominan variabel bebas yang diteliti terhadap varabel terikat, sedangkan analisis diskriminan digunakan untuk melihat besarnya tingkat perbedaan variabel bebas yang mempengaruhi variabel terikat. Rasio keuangan Debt to Equity Ratio (DER) yang dominan mempengaruhi kolektibiliti nasabah pada PT. Bank Negara Indonesia (Persero) Tbk Sentra Kredit Kecil Makassar. Hubungan antara kolektibiliti dengan penilaian keuangan yang sesuai dengan perangkat aplikasi kredit pada PT. Bank Negara Indonesia (Persero) Tbk Sentra Kredit Kecil Makassar. Terlihat dari kolektibiliti credit performing dan non performing loan dipengaruhi oleh variabel bebas aktiva lancar dan DER.
\end{abstract}

Kata kunci: Pemberian Kredit, Risiko Macet, dan Kolektif.

\section{Abstract}

This research aim to know credit at PT. Bank Negara Indonesia (Persero) Tbk Sentra Kredit Kecil Makassar has a low collectibility, to know the dominant financial ratios will affect the collectibility of customers at PT. Bank Negara Indonesia (Persero) Tbk Sentra Kredit Kecil Makassar and to know the relationship between collectibilities with financial valuation in accordance with credit application tools at PT. Bank Negara Indonesia (Persero) Tbk Sentra Kredit Kecil Makassar.

This research uses quantitative approach with regression analysis to see the dominant influence of independent variables that are studied on bound varabel, while discriminant analysis is used to see the level of difference of independent variable affecting the dependent variable. The dominant Debt to Equity Ratio (DER) ratio affects the collectibility of customers at PT. Bank Negara Indonesia (Persero) Tbk Sentra Kredit Kecil Makassar. The relationship between collectibilities and financial valuations in accordance with credit application tools at PT. Bank Negara Indonesia (Persero) Tbk Sentra Kredit Kecil Makassar. Seen from the collectibility of credit performing and non performing loan is influenced by the variable of current assets and DER.

Keywords: Credit Lending, Loss Risk, and Collective. 


\section{PENDAHULUAN}

\section{A. Latar Belakang}

Lembaga keuangan perbankan mempunyai peranan yang amat penting dalam perekonomian suatu negara. Perbankan mempunyai kegiatan mempertemukan pihak yang membutuhkan dana (borrower) dengan pihak yang mempunyai kelebihan dana (saver). Melalui kegiatan perkreditan, bank berusaha memenuhi kebutuhan masyarakat bagi kelancaran usahanya, sedangkan dengan kegiatan penyimpanan dana, bank berusaha menawarkan kepada masyarakat akan keamanan dananya dengan jasa yang diperoleh. Bank cenderung memandang sektor riil masih kurang hati-hati dalam melakukan ekspansi usaha, sehingga akhirnya perbankan enggan mengucurkan pinjaman ke sektor riil.

Kalangan perbankan tidak mau mengulang masa lalu, dimana laju pertumbuhan pinjaman sangat tinggi dengan tingkat risiko yang sangat tinggi pula, sehingga menyebabkan angka Non Performing Loan (NPL) meningkat, yang pada akhirnya telah menyeret dunia perbankan ke dalam krisis yang berkepanjangan. Salah satu upaya untuk mencegah terjadinya kredit macet/bermasalah (Non Performing Loan) adalah diperlukannya perangkat analisis kredit yang lebih komprehensif dan aplikabel agar dapat memprediksi risiko perusahaan. Agar perbankan terutama Bank BNI dapat terus menjalankan perannya sebagai financial intermediary institution yaitu lembaga yang berperan sebagai penyimpan dan penyalur keuangan maka perlu pengelolaan lebih lanjut dari sisi penyaluran keuangan (kredit). Supaya peran tersebut dapat terus dilaksanakan, maka perlu pengelolaan lebih teliti dan hati-hati dalam penyaluran kredit tersebut.

\section{B. Rumusan Masalah Penelitian}

Berdasarkan latar belakang masalah yang diuraikan diatas, maka yang menjadi pokok permasalahan dalam penelitian ini adalah ada beberapa debitur yang mengalami kesulitan dalam pembayaran bunga maupun pokok pinjaman yang telah disepakati sebelumnya dengan pihak Bank BNI walaupun pemberian kredit telah dilakukan secara prudensial atau hatihati yaitu sesuai norma-norma pemberian kredit yang berlaku, yang dapat dijabarkan ke dalam pertanyaan sebagai berikut:

1. Bagaimana mengetahui kredit di PT. Bank Negara Indonesia (Persero) Tbk Sentra Kredit Kecil Makassar memiliki kolektibiliti rendah?

2. Manakah variabel bebas yang dominan akan mempengaruhi kolektibiliti nasabah pada PT. Bank Negara Indonesia (Persero) Tbk Sentra Kredit Kecil Makassar?

3. Apakah ada hubungan antara kolektibiliti dengan penilaian keuangan yang sesuai dengan perangkat aplikasi kredit pada PT. Bank Negara Indonesia (Persero) Tbk Sentra Kredit Kecil Makassar?

\section{TINJAUAN TEORI}

\section{A. Pengertian Kredit}

Istilah kredit berasal dari bahasa Yunani "credere" yang berarti kepercayaan. Kredit tanpa kepercayaan tidak mungkin dapat terjadi. Dalam dunia perbankan, kepercayaan dapat diberikan atau diterima dalam bentuk uang. Pihak-pihak yang berhubungan dalam transaksi kredit itu adalah yang memberikan kredit yang biasanya berbentuk perseroan maupun badan usaha atau badan hukum (PT, CV, Firma dan sebagainya).

Istilah yang biasanya digunakan dalam dunia perbankan untuk pemberi kredit disebut kreditur, sedangkan untuk penerima kredit disebut debitur. Kredit mempercayai debitur untuk memberikan 
kredit, dalam hal ini berbentuk uang. Atas pemberian kredit tersebut kreditur menuntut prestasi dari debitur yang biasanya disebut bunga.

Berdasarkan dari uraian singkat diatas, dapatlah disimpulkan arti dari kredit, yaitu merupakan suatu pemberian prestasi oleh suatu pihak kepada pihak lain dan prestasi itu akan dikembalikan lagi pada waktu tertentu yang akan datang dengan disertai kontra prestasi yang berupa bunga.

Pengertian kredit sesuai UndangUndang Pokok Perbankan No. 2 Tahun 1992 yang kemudian diubah menjadi Undang-Undang No.10 Tahun 1998, memberikan definisi sebagai berikut " Kredit adalah penyediaan uang atau tagihan-tagihan yang dapat disamakan dengan itu berdasarkan persetujuan atau kesepakatan pinjam meminjam antara bank dengan pihak lain, yang mewajibkan pihak peminjam berkewajiban melunasi hutangnya, setelah jangka waktu tertentu dengan jumlah bunga, imbalan atau pembagian hasil keuntungan."

Dengan demikian, untuk suatu persetujuan kredit diterima, maka harus memenuhi kriteria sebagai berikut :

1. Terdapat persetujuan pinjam meminjam antar kreditur dengan debitur.

2. Mempunyai jangka waktu tertentu.

3. Hak Kreditur untuk menuntut dan memperoleh pembayaran serta kewajiban debitur utnuk membayar prestasi yang diterima.

Analisis kredit amat penting karena dapat digunakan untuk :

1. Menentukan berbagai risiko yang dihadapi oleh bank dalam memberikan kredit kepada seseorang atau badan usaha.

2. Mengantisipasi kemungkinan pelunasan kredit tersebut karena bank telah mengetahui kemampuan pelunasan melalui analisis cashflow usaha debitur.
3. Mengetahui jenis kredit, jumlah kredit, dan jangka waktu kredit yang dibutuhkan oleh usaha debitur, sehingga bank dapat melakukan penyesuaian dengan struktur dana yang ready for use (melayani lending demand).

4. Mengetahui kemampuan dan kemauan debitur untuk melunasi kreditnya, baik dari sumber pelunasan primer maupun skunder.

Selanjutnya menurut Moh. Tjoekam (1994:94) pada dasarnya konsep 5 C yaitu : Charakter (watak), Capaciti (kemampuan), Capital (modal), Collateral (jaminan), Condition of Economic. Disamping konsep $5 \mathrm{C}$ tersebut diatas Kasmir (2008:110) juga menjelaskan metode analisi "7 $\mathrm{P}$ Principles" yaitu Personality, Purpose, Payment, Protection Prospect, Party dan Profitability.

\section{B. Aspek-Aspek Penilaian Kredit}

Disamping konsep dan prisnsip penilaian kredit diatas, maka dalam melakukan analisis kredit juga dilakukan penilaian atas beberapa aspek yang menyangkut kegiatan usaha calon debitur yaitu: 1. Aspek Umum, 2. Aspek managemen dan Organisasi, 3. Aspek Pemasaran dan 4. Aspek Teknis dan Produksi.

\section{Fungsi Kredit}

Undang-undang No.7 Tahun 1992 menyebutkan bank adalah lembaga keuangan yang usaha pokoknya adalah memberikan kredit dan jasa-jasa dalam lalu lintas pembayaran dan peredaran uang. Secara umum fungsi kredit dalam kehidupan perekonomian dan perdagangan menurut Thomas Suyatno, H. A. Chalik, Made Sukada, C. Tinon Yuniati Ananda dan Djuhaepah T. Marala (1999:16) adalah sebagai berikut:

1. Kredit pada hakikatnya dapat meningkatkan daya guna uang.

2. Kredit dapat meningkatkan peredaran dan lalulintas uang 
3. Kredit dapat pula meningkatkan daya guna dan peredaran barang.

4. Kredit sebagai salah satu stabilitas ekonomi.

5. Kredit dapat meningkatkan kegairahan berusaha.

6. Kredit dapat meningkatkan pemerataan pendapatan.

7. Kredit sebagai alat untuk meningkatkan hubungan internasional.

\section{Jenis-Jenis Kredit}

Pembagian jenis-jenis kredit tidak didasarkan pada pengertian yang terkandung dalam arti kredit itu, tetapi pembagian itu lebih ditekankan pada faktor-faktor dan unsur-unsur serta kegunaan yang terdapat dalam pengertian kredit, oleh karena itu jenisjenis kredit dikelompokkan menjadi sebagai berikut:

1. Menurut tujuan penggunaannya. (Kredit Konsumtif dan Kredit Produktif).

2. Menurut sifat penarikannya. Kebutuhan pembiayaan itu secara garis besar dibagi atas: (Kredit Rekening Koran dan Kredit dengan angsuran atau aflopend).

3. Menurut Jangka waktunya. (Kredit Jangka Pendek (Short-Term Loan), Kredit Jangka Menengah (MediumTerm Loan), dan Kredit Jangka Panjang (Long-Term Loan)

4. Menurut sifat pelunasannya. (Kredit dengan angsuran dan Kredit tanpa angsuran).

\section{METODE PENELITIAN}

\section{A. Jenis Dan Sumber Data}

Penelitian ini menggunakan data sekunder (secondary data) diperoleh dari laporan-laporan keuangan (Neraca dan Perhitungan Laba Rugi) yang telah digunakan dalam proses analisa kredit

$\mathrm{D}=$ Skor diskriminan

$$
\mathrm{D}=\mathrm{b}_{\mathrm{o}}+\mathrm{b}_{1} \mathrm{X}_{1}+\mathrm{b}_{2} \mathrm{X}_{2}+\mathrm{b}_{3} \mathrm{X}_{3}+\mathrm{b}_{4} \mathrm{X}_{4}+\ldots \ldots \ldots \mathrm{b}_{\mathrm{k}} \mathrm{X}_{\mathrm{k}}
$$

$\mathrm{B}=$ Koefisien diskriminan

$\mathrm{X}=$ Variabel bebas masing-masing debitur dengan teknik observasi, wawancara dan teknik kepustakaan. Metode Penentuan Sampel dengan menggunakan debitur ritel market PT. Bank Negara (Persero) Tbk Sentra Kredit Kecil Makassar per 31 Desember 2017 sebanyak 40 (empat puluh) debitur sesuai segmentasinya yang telah menjadi debitur minimal 2 tahun dengan pemilihan sample secara probabilitas dengan metode Stratified Random Sampling (Pemilihan Sampel Acak Berdasarkan Strata).

\section{B. Metode Analisis}

Metode analisis yang digunakan untuk menguji hipotesis yang dikemukakan sebelumnya berupa metode kuantitatif. Model analisis yang digunakan untuk manialai sampai pada tahapan pengukuran tingkat risiko perusahaan berdasarkan penilaian terhadap indikator-indikator kinerja keuangan perusahaan yaitu analisa Rasio Keuangan. Rasio keuangan yang dijadikan rasio kunci sebagaimana yang dijadikan acuan Bank BNI saat ini terdiri dari rasio likuiditas (CR minimal 1,2 kali) dan ratio leverage (DER maksimal 2 kali). Berdasarkan data-data yang diperoleh dari penilaian rasio dan penilaian kualitatif tersebut, dianalisis kedalam bentuk analisis diskriminan (Discriminant Analysis). Dalam penelitian ini dipergunakan Discriminant Analysis metode sederhana yaitu mempergunakan variabel tidak bebas dengan dua kategori yaitu lancar dan tidak lancar.

Adapun model analisis diskriminan secara umum yang melibatkan kombinasi dari beberapa variabel bebas yang telah disebutkan di atas tadi dalam bentuk sebagai berikut: 
Apabila diterapkan pada penelitian ini adalah sebagai berikut: penelitian ini maka rumus umum dari

$\mathrm{D}=\mathrm{b}_{0}+\mathrm{b}_{1} \mathrm{AL}+\mathrm{b}_{2} \mathrm{HL}+\mathrm{b}_{3} \mathrm{TH}+\mathrm{b}_{4} \mathrm{TM}+\mathrm{b}_{5} \mathrm{TA}+\mathrm{b}_{6} \mathrm{EAT}+\mathrm{b}_{7} \mathrm{PM}+\mathrm{b}_{8} \mathrm{CR}+\mathrm{b}_{9} \mathrm{QR}+$ $b_{10}$ DER $+b_{11}$ ITO $+b_{12} A C P+b_{13}$ ROA $+b_{14}$ ID $+E$

Adapun statistik yang berkenaan dengan Discriminant Analysis berdasarkan penggunaan SPSS R-10.05 adalah sebagai berikut : Canonical Correlation, Centroid, Classification Matrix, Discriminan Function Coefficient, Discriminant Score, Eigenvalue, F-Value, Group Means dan Group Standard deviation, Pooled Within-group Correlation Matrix, Standardized Discriminant Function Coefficients, Structur Correlation, Total correlation matrix, Wilks' $\lambda$.

HASIL PENELITIAN DAN PEMBAHASAN

\section{A. Pelaksanaan Pemberian Kredit pada PT. Bank Negara Indonesia (Persero) Tbk Sentra Kredit Kecil Makassar}

Analisa kredit merupakan
pondasi dari sistem manajemen
perkreditan bank, sehingga dijadikan dasar untuk mengendalikan risiko, menetapkan struktur kredit yang diberikan dan sarana pengambilan keputusan kredit yang sehat (ditinjau dari riwayat pembayaran, hasil prestasi dan kecukupan jaminan). Tujuan dari proses analisa kredit adalah menyediakan sarana atau perangkat analisa kredit (PAK) yang efektif dan efisien dalam rangka pemutusan kredit

$$
\begin{gathered}
Y=946.242+0.633 X_{1}+0.708 X_{2}+0.674 X_{3}+0.602 X_{4}+0.818 X_{5} \\
+0.764 X_{6}+0.731 X_{7}+0.593 X_{8}+0.920 X_{9}+0.615 X_{10}+0.626 X_{11} \\
+0.782 X_{12}+0.837 X_{13}
\end{gathered}
$$

Interpretasi dari persamaan regresi berganda di atas tersebut dapat diuraikan sebagai berikut:

1. Nilai konstanta sebesar 946.242 yang menyatakan bahwa nilai untuk variabel terikat sebesar 946.242 ditentukan oleh aktiva lancar, hutang lancar, total hutang, total modal, omzet, EAT, \%PM, QR, DER, ITO, ACP, ROA, ID. secara sehat. Proses analisa kredit retail market Bank BNI terdiri dari 6 (enam) langkah kegiatan sebagai berikut: 1 . Pengumpulan data, 2. Verifikasi data, 3. Analisa laporan keuangan, 4. Evaluasi kebutuhan keuangan, 5. Struktur fasilitas kredit.

\section{B. Analisis Kinerja Keuangan}

Analisa laporan keuangan bertujuan untuk mengetahui kondisi, perkembangan dan potensi keuangan debitur yang dicantumkan dalam formulir analisis keuangan. Laporan keuangan nasabah/debitur yang dianalisis adalah laporan keuangan selama 3 tahun terakhir. Lingkup pembahasan analisis kinerja keuangan terdiri dari : 1. Analisa Rasio Ikhtisar Keuangan, 2. Analisa Laba Rugi dan Neraca, 3. Analisis Rekonsiliasi Modal dan Harta Tetap, 4. Analisa Pernyataan Pengadaan Kas.

\section{Analisis Regresi Linear Berganda}

Setelah data-data yang ada terkumpul yang telah dilakukan analisis diskriminan, maka selanjutnya dilakukan pengolahan data. Data-data tersebut diolah melalui persamaan Regresi Linier Berganda, sehingga diperoleh hasil yang diformulasikan dalam bentuk persamaan berikut ini:
2. Koefisien regresi untuk variabel $X_{1}$ (aktiva lancar) sebesar 0.633 menunjukkan bahwa aktiva lancar berpengaruh signifikan positif terhadap pengurangan risiko kemacetan dalam pemberian kredit pada PT. BNI (Persero) Tbk. Sentra Kredit Kecil Makassar, dengan tingkat Sig. 0.043. 
3. Koefisien regresi untuk variabel $\mathrm{X}_{2}$ (hutang lancar) sebesar 0.708 menunjukkan bahwa hutang lancar berpengaruh signifikan positif terhadap pengurangan risiko kemacetan dalam pemberian kredit pada PT. BNI (Persero) Tbk. Sentra Kredit Kecil Makassar, dengan tingkat Sig. 0.041.

4. Koefisien regresi untuk variabel $\mathrm{X}_{3}$ (total hutang) sebesar 0.674 menunjukkan bahwa total hutang berpengaruh signifikan positif terhadap pengurangan risiko kemacetan dalam pemberian kredit pada PT. BNI (Persero) Tbk. Sentra Kredit Kecil Makassar, dengan tingkat Sig. 0.042.

5. Koefisien regresi untuk variabel $\mathrm{X}_{4}$ (total modal) sebesar 0.602 menunjukkan bahwa total modal berpengaruh signifikan positif terhadap pengurangan risiko kemacetan dalam pemberian kredit pada PT. BNI (Persero) Tbk. Sentra Kredit Kecil Makassar, dengan tingkat Sig. 0.048.

6. Koefisien regresi untuk variabel $\mathrm{X}_{5}$ (omzet) sebesar 0.818 menunjukkan bahwa aktiva lancar berpengaruh signifikan positif terhadap pengurangan risiko kemacetan dalam pemberian kredit pada PT. BNI (Persero) Tbk. Sentra Kredit Kecil Makassar, dengan tingkat Sig. 0.013.

7. Koefisien regresi untuk variabel $\mathrm{X}_{6}$ (EAT) sebesar 0.764 menunjukkan bahwa EAT berpengaruh signifikan positif terhadap pengurangan risiko kemacetan dalam pemberian kredit pada PT. BNI (Persero) Tbk. Sentra Kredit Kecil Makassar, dengan tingkat Sig. 0.034.

8. Koefisien regresi untuk variabel $\mathrm{X}_{7}$ (\% PM) sebesar 0.731 menunjukkan bahwa \% PM berpengaruh signifikan positif terhadap pengurangan risiko kemacetan dalam pemberian kredit pada PT. BNI (Persero) Tbk. Sentra
Kredit Kecil Makassar, dengan tingkat Sig. 0.038.

9. Koefisien regresi untuk variabel $X_{8}$ (QR) sebesar 0.593 menunjukkan bahwa QR berpengaruh signifikan positif terhadap pengurangan risiko kemacetan dalam pemberian kredit pada PT. BNI (Persero) Tbk. Sentra Kredit Kecil Makassar, dengan tingkat Sig. 0.049.

10. Koefisien regresi untuk variabel $X_{9}$ (DER) sebesar 0.920 menunjukkan bahwa DER berpengaruh signifikan positif terhadap pengurangan risiko kemacetan dalam pemberian kredit pada PT. BNI (Persero) Tbk. Sentra Kredit Kecil Makassar, dengan tingkat Sig. 0.000.

11. Koefisien regresi untuk variabel $X_{10}$ (ITO) sebesar 0.615 menunjukkan bahwa ITO berpengaruh signifikan positif terhadap pengurangan risiko kemacetan dalam pemberian kredit pada PT. BNI (Persero) Tbk. Sentra Kredit Kecil Makassar, dengan tingkat Sig. 0.045.

12. Koefisien regresi untuk variabel $X_{11}$ (ACP) sebesar 0.626 menunjukkan bahwa ACP berpengaruh signifikan positif terhadap pengurangan risiko kemacetan dalam pemberian kredit pada PT. BNI (Persero) Tbk. Sentra Kredit Kecil Makassar, dengan tingkat Sig. 0.040.

13. Koefisien regresi untuk variabel $\mathrm{X}_{12}$ (ROA) sebesar 0.782 menunjukkan bahwa ROA berpengaruh signifikan positif terhadap pengurangan risiko kemacetan dalam pemberian kredit pada PT. BNI (Persero) Tbk. Sentra Kredit Kecil Makassar, dengan tingkat Sig. 0.026.

14. Koefisien regresi untuk variabel $X_{13}$ (ID) sebesar 0.837 menunjukkan bahwa ID berpengaruh signifikan positif terhadap pengurangan risiko kemacetan dalam pemberian kredit pada PT. BNI (Persero) Tbk. Sentra 
Kredit Kecil Makassar, dengan tingkat Sig. 0.000.

Sesuai persamaan regresi linier berganda tersebut di atas, dapat diketahui bahwa rasio keuangan yang dominan mempengaruhi kolektibiliti nasabah pada PT. Bank Negara Indonesia (Persero) Tbk Sentra Kredit Kecil Makassar adalah DER (debt to equity ratio).

\section{Analisis Diskriminatif}

Untuk kredit lancar, maksimum kredit yang ada pada saat ini adalah sebesar Rp. 3 Milyar dan maksimum kredit yang mengalami macet adalah $\mathrm{Rp}$. 1.5 Milyar. Dari pelaksanaan kredit yang selama ini dilaksanakan, besar atau kecilnya kredit yang diberikan terutama sekali didasarkan atas kriteria kondisi usaha dan besarnya jaminan yang diberikan oleh debitur sebagai penutup kredit. Tabel 5.1 diperoleh bahwa secara keseluruhan maksimum kredit yang diberikan adalah sebesar Rp. 3 Milyar (lancar) dan minimum kredit adalah Rp. 175 juta (tidak lancar atau macet).

Tabel 1. Statistik Deskriptif dari Maksimum Kredit

\begin{tabular}{|ll|r|r|}
\hline & & Maksimum Kredit & Valid N (listwise) \\
\hline $\mathrm{N}$ & Statistic & 40 & \\
\hline Range & Statistic & 2825 & \\
\hline Minimum & Statistic & 175 & \\
\hline Maximum & Statistic & 3000 & \\
\hline Sum & Statistic & 33997 & \\
\hline Mean & Statistic & 849.92500 & \\
& Std. Error & 97.90923 & \\
\hline Std. Deviation & Statistic & 619.23234 & \\
\hline Variance & Statistic & 383448.68654 & \\
\hline Skewness & Statistic & 1.63949 & \\
& Std. Error & .37378 & \\
\hline Skewness & Statistic & 2.82173 & \\
& Std. Error & .73260 & \\
\hline
\end{tabular}

Sumber: Data setelah diolah.

Kolektibility pinjaman dari kelompok non performing loan memperlihatkan bahwa nilai tengah (mean) terbesar ditunjukkan oleh omzet yaitu sebesar 2255.000 (standard deviation $=1743.62145)$ dan terkecil nilai tengahnya adalah persentase dari profit margin yaitu 0.02709 (standard deviation $=.07667$ ). Sedangkan untuk kelompok kolektibilitas performing loan nilai tengah (mean) terbesar ditunjukkan oleh omzet yaitu sebesar 5710.73333 (standard deviation $=5073.20726)$ dan terkecil nilai tengahnya adalah persentase dari profit margin yaitu 0.05893 (standard deviation $=0.03661$ ) . Asumsi yang dipergunakan dalam Discriminant Analysis adalah bahwa keragaman antar variabel adalah sama (equal variances), oleh karena itu diskriminan yang baik memperlihatkan simpanan baku yang tidak terlalu jauh besarnya antar sesama kelompok.

Untuk melihat hubungan yang ada antara sesama variabel bebas dalam diskriminan analisis ditunjukkan pada Lampiran 5 yaitu berupa pengujian dari matriks covarian (covariance matrix) dan korelasi (correlation), diperoleh dari rata-rata pemisahan covariance matrix untuk seluruh kelompok variabel bebas, sedangkan korelasi yang dihasilkan diperoleh dari keragaman dan covariance yang terdapat dalam kelompok yang berguna untuk melihat ada atau tidaknya terjadi multikolineriatas antar sesama variabel bebas. Apabila sesama variabel bebas di uji akan memperlihatkan nilai korelasi $=1$.

Nilai dari Covariance Matrix ini digambarkan pada diagonal utama dari variabel bebas yang bersangkutan, dan nilai-nilai yang ada di atas dari diagonal 
utama dicerminkan pula pada bagian bawah diagonal utama dengan kata lain nilai-nilai yang ada di atas atau di bawah diagonal utama adalah sama. Sedangkan nilai korelasi antara sesama variabel bernilai 1 karena antara sesama variabel terjadi hubungan yang sempurna. Dari Tabel 5.5 tersebut diperoleh bahwa pembeda antara diagonal dari correlation

Tabel 5.5 Uji Kesamaan antara Variabel Tidak Bebas dengan Kriteria Log Determinant.

\begin{tabular}{|l|r|r|}
\hline Collectibility & Rank & Log Determinant \\
\hline Non Performing Loan & 2 & 11.0195 \\
Performing Loan & 2 & 11.69132 \\
Pooled within-groups & 2 & 12.25115 \\
\hline
\end{tabular}

The ranks and natural logarithms of determinants printed are those of the group covariance matrices.

Pada penelitian ini dipergunakan sebanyak 14 variabel bebas yaitu mulai dan Aktiva lancar, hutang lancar, total hutang, total modal, total aktiva, omzet, eat, prosenstase profit margin, current ratio, quick ratio, debt to equity ratio, inventory turn over, average collection period dan return on assets. Dari keempat belas variabel bebas ini, berdasarkan Tabel 5.9 diperoleh gambaran bahwa variabel bebas Debt to Equity Ratio dan aktiva lancar merupakan variabel yang disertakan (entered) dan variabel yang tidak diikutsertakan (removed) dalam discriminant analysis. Untuk menentukan variabel bebas mana yang disertakan atau dikeluarkan, seperti yang terlihat pada Tabel 5.7 dipergunakan statistik uji Min. D. Squared. Pada bagian footnore dari Tabel 5.7 dijelaskan jumlah langkah yang telah ditempuh untuk analisis sebanyak 38 langkah, dengan nilai $\mathrm{F}$ uji adalah $5 \%$ dan nilai minimum dari nilai $F$ uji untuk mengeluarkan variabel bebas adalah 10\%. Dari Tabel 5.7 dapat dilihat bahwa nilai sig. dari DER adalah .00604 dan Aktiva lancar adalah .00324.

$$
\text { Untuk mengukur derajat }
$$

keberhasilan dari pengelompokkan atas sampel data yang ada dapat dilihat pada Tabel 5.20. Jumlah data sesungguhnya tersebut dicirikan dengan angka 1. Nilai kovarian terbesar diperoleh dari variabel bebas omzet dengan nilai 2609553.921 sedangkan korelasi yang terbesar diperoleh dari total modal sebesar .795 atau $63,2025 \%$ dari variabel ini dapat menjelaskan hubungan yang terjadi antara sesama variabel bebas.

yang berhasil dikelompokkan kedalam kategori kolektibiliti non performing loan dengan keanggotaan kelompok dari data diprediksi non performing loan secara tepat sebanyak $7(70 \%)$, dan yang tidak tepat sebanyak $3(30 \%)$ data. Dilain pihak Untuk data sesungguhnya dari performing loan yang berhasil dikelompokkan kedalam keanggotaan kelompok prediksi non performing loan secara tepat sebanyak $5(16,67 \%)$ dan tidak tepat sejumlah $25 \quad(83,33 \%)$. Sehingga secara keseluruhan data yang berjumlah $40(100 \%)$ data seluruhnya telah berhasil mempunyai kelompoknya masing-masing.

Dari Tabel 5.20 juga menjelaskan, setelah melalui suatu validasi ulang, maka komposisi data yang ada berubah sehinggga data sesungguhnya dari kolektibiliti kredit non performing loan dengan keanggotaan kelompok prediksi non performing loan yang dikelompokkan secara tepat sejumlah $6 \quad(60 \%)$ dan dikelompokkan secara tidak tepat sejumlah $4(40 \%)$. Lalu untuk data yang sesungguhnya dari performing loan memberikan nilai keanggotaan bagi kelompok non performing yang diprediksi dikelompokkan secara tepat sebanyak $6 \quad(60 \%)$ dan tidak tepat sejumlah $24(80 \%)$. Hal ini juga berarti 
ada terjadi kesalahan pengelompokkan yang terjadi dimana ada satu yang salah

pengelompokkan kedalam data prediksi non performing dan performing loan.

Tabel 5.2 Pengelompokkan Hasil Discriminant Analysis

\begin{tabular}{|c|c|c|c|c|c|}
\hline & & \multirow[b]{2}{*}{ Collectibility } & \multicolumn{2}{|c|}{ Predicted Group Membership } & \multirow[b]{2}{*}{ Total } \\
\hline & & & Non Performing Loan & Performing Loan & \\
\hline \multirow[t]{4}{*}{ Original } & Count & Non Performing Loan & 7 & 3 & 10 \\
\hline & & Performing Loan & 5 & 25 & 30 \\
\hline & $\%$ & Non Performing Loan & 70.00000 & 30.00000 & 100.0 \\
\hline & & Performing Loan & 16.66667 & 83.33333 & 100.0 \\
\hline \multirow[t]{4}{*}{ Cross-validated $^{\mathrm{a}}$} & Count & Non Performing Loan & 6 & 4 & 10 \\
\hline & & Performing Loan & 6 & 24 & 30 \\
\hline & $\%$ & Non Performing Loan & 60.00000 & 40.00000 & 100.0 \\
\hline & & Performing Loan & 20.00000 & 80.00000 & 100.0 \\
\hline
\end{tabular}

a. Cross validations is done only for those cases in the analysis. In cross validation, each case is classified by the functions derived from all cases other than that case.

b. $80.0 \%$ of original grouped cases correctly classified.

c. $75.0 \%$ of cross-validated grouped cases correctly classified.

Secara keseluruhan persentase yang berhasil dikelompokkan sesuai dengan penggolongannya sebesar $80.0 \%$. Hal ini terlihat sangat optimises, oleh karena itu dipergunakan metode Leave-one-out classification sehingga nilai derajat keberhasilan dalam pengelompokkan data yang ada menjadi $75.0 \%$ setelah melalui validasi ulang. Pemakaian metode Leave-one-out classification ini sebenarnya memprediksikan kasus yang ada sesuai dengan fungsi persamaan diskriminan yang diperoleh terhadap data yang sebenarnya.

\section{SIMPULAN DAN SARAN}

\section{A. Simpulan}

Berdasarkan hasil dan pembahasan di atas, maka kesimpulan penelitian ini adalah:

1. Kredit di PT. Bank Negara Indonesia (Persero) Tbk Sentra Kredit Kecil Makassar memiliki kolektibiliti rendah yang ditunjukkan dari besarnya nilai canonical correlation dari fungsi diskriminant yang berarti variasi yang terjadi terhadap keberhasilan pengelolan debitur dapat dijelaskan dengan menggunakan aktiva lancar dan DER.

2. Rasio keuangan Debt to Equity Ratio (DER) yang dominan mempengaruhi kolektibiliti nasabah pada PT. Bank Negara Indonesia (Persero) Tbk
Sentra Kredit Kecil Makassar berdasarkan hasil analisis regresi linier berganda menunjukkan nilai koefisien regresi untuk variabel $\mathrm{X}_{9}$ (DER) sebesar 0.920 yang berarti DER berpengaruh signifikan positif terhadap pengurangan risiko kemacetan dalam pemberian kredit pada PT. BNI (Persero) Tbk. Sentra Kredit Kecil Makassar, dengan tingkat Sig. 0.000 .

3. Hubungan antara kolektibiliti dengan penilaian keuangan yang sesuai dengan perangkat aplikasi kredit pada PT. Bank Negara Indonesia (Persero) Tbk Sentra Kredit Kecil Makassar. Terlihat dari collectibility credit performing dan non performing loan dipengaruhi oleh variabel bebas aktiva lancar dan DER.

\section{B. Saran}

1. Agar kualitas penyaluran kredit dapat berjalan dengan baik, maka pihak manajemen Bank BNI Kantor Cabang Makassar hendaknya lebih memperhatikan kriteria penilaian dari aktiva lancar dan DER sebelum memutuskan untuk memberikan kredit.

2. Untuk lebih memastikan ukuran yang sebenarnya dari kualitas pemberian kredit ini, hendaknya dilakukan pengkajian terhadap faktor kualitatif lainnya seperti integritas 
manajemen, kemampuan melakukan usaha dan pengalaman usaha, di mana nilai-nilai subyektivitas yang ada dapat dikuantifisir dengan membuat suatu skala pengukuran yang standar.

3. Disarankan penelitian ini dapat menjadi referensi bagi peneliti yang akan datang yang minat meneliti mengenai bauran pemasaran terhadap pengambilan keputusan pada obyek penelitian yang lain.

\section{DAFTAR PUSTAKA}

Aczel, A. D., Complete Business Statistics. Richard D. Irwin, USA, 1999.

Afifi A. A., and Clark V., Computer Aided Multivariate Analysis. Third Edition, Chapman \& Hall, 1999.

Algifari, Analisis Statistic untuk Bisnis. Edisi Pertama, NPFE Yogyakarta, 1997.

Boediono, Wayan Koster, Teori dan Aplikasi Statistika \& Probabilitas. Cetakan 1, PT. Remadja Rosdakarya Bandung, 2001.

Checkley, K., dan Jury T, Advanced Credit Analysis. Euromoney Books PLC Nestor House, London, 1996.

Darmawi, Hermawan, Manajemen Risiko, Cetakan Kesepuluh, Bumi Aksara, Jakarta, 2006.

Dillon, W. R., and Goldstein M., Multivariate Analysis: Method and Applications, John Wiley and Sons, New York, 1998.

Firdaus H, Rahmat dan Ariyanti Maya, Manajemen Perkreditan Bank Umum, Cetakan Kedua, Alfabeta, 2004.

Foster, George, Financial Statement Analysis. Prentice-Hall International Edition, $2^{\text {nd }}, 1986$.

Kadri, Sartono, Analysis Kredit Bermasalah Penyelamatan
Kredit dan Penyelesaian Kredit. Institut Bankir Indonesia, Jakarta, 1996.

Idrus, Ferry N, Manajemen Risiko Perbankan. PT. Raja Grafindo Persada, Jakarta, 2008.

Kertonegoro, Sentanoe, Manajemen Risiko dan Asuransi. Cetakan Pertama, PT. Toko Gunung Agung, Jakarta, 1996.

Sofyan, Iban, Manajemen Risiko. Cetakan Pertama, Graha Ilmu, Yogyakarta, 2005.

Latumaerissa, Julius R, Mengenal Aspek-aspek Operasi Bank Umum. Cetakan Pertama, Bumi Aksara, Jakarta, 1999.

Maholtra, N.K, Marketing Research An Applied Oriented. International Edition, Prentice Hall International Inc.

Sutarno, Aspek-aspek Hukum Perkreditan pada Bank. Cetakan Ketiga, CV. Alfabeta, Bandung, 2005.

Riyanto, Bambang, Dasar-dasar Pembelanjaan Perusahaan. Edisi Keempat, Cetakan Keenam, BPFE-Yogyakarta, 1999.

Ruky, Saiful M, Menilai Penyertaan dalam Perusahaan (Business aluation: Valuation of CloselyHeld Business and Business Ownership Internest), PT. Gramedia Pustaka Utama, Jakarta, 1999.

Siagian, Dergibson, Sugiarto, Metode Statistika Untuk Bisnis dan Ekonomi. PT. Gramedia Pustaka Utama, Jakarta, 2000.

Soediyono, R, Analisa Laporan Keuangan: Analisis Rasio. Liberty Yogyakarta, 1999.

Suyatno, Thomas, Chalid, H.A., Sukada, Made, Ananda, Tinon Ynianti dan Marala, Djuhaepah $\mathrm{T}$, Dasar-dasar Perkreditan. Edisi Keempat, PT. Gramedia Pustaka Utama, 1999. 
Kasmir, Bank dan Lembaga Keuangan Lainnya. PT. Raja Grafindo Persada, Jakarta, 2008.

Tabachnick B.G dan Fidell, L.S., Using Multivariate Statistics. $3^{\text {rd }}$ Edition, Harper Collins College, New York, 1996.

Tjoekam, Moh, H, Kredit Perbankan di Indonesia. Cetakan Pertama, Andi Yogyakarta, 2000.

White, G.I, Sondhi, A.C., dan Fried, D, The Analysis and Use of Financial Statements, 2rd Edition, John Wiley and Sons, Inc., 1997. 